\title{
EVALUATING LIQUEFACTION POTENTIAL OF PUMICEOUS DEPOSITS THROUGH FIELD TESTING: CASE STUDY OF THE 1987 EDGECUMBE EARTHQUAKE
}

\author{
Rolando P. Orense ${ }^{1}$, Mohammad B. Asadi², \\ Mark E. Stringer ${ }^{3}$ and Michael J. Pender ${ }^{4}$
}

(Submitted August 2019; Reviewed December 2019; Accepted March 2020)

\begin{abstract}
Pumice materials, which are problematic from an engineering viewpoint, are widespread in the central part of the North Island. Considering the impacts of the 2010-2011 Christchurch earthquakes, a clear understanding of their properties under earthquake loading is necessary. For example, the 1987 Edgecumbe earthquake showed evidence of localised liquefaction of sands of volcanic origin. To elucidate on this, research was undertaken to investigate whether existing empirical field-based methods to evaluate the liquefaction potential of sands, which were originally developed for hard-grained soils, are applicable to crushable pumice-rich deposits. For this purpose, two sites, one in Whakatane and another in Edgecumbe, were selected where the occurrence of liquefaction was reported following the Edgecumbe earthquake. Manifestations of soil liquefaction, such as sand boils and ejected materials, have been reported at both sites. Field tests, including cone penetration tests (CPT), shear-wave velocity profiling, and screw driving sounding (SDS) tests were performed at the sites. Then, considering estimated peak ground accelerations (PGAs) at the sites based on recorded motions and possible range of ground water table locations, liquefaction analysis was conducted at the sites using available empirical approaches. To clarify the results of the analysis, undisturbed soil samples were obtained at both sites to investigate the laboratory-derived cyclic resistance ratios and to compare with the field-estimated values. Research results clearly showed that these pumice-rich soils do not fit existing liquefaction assessment frameworks and alternate methods are necessary to characterise them.
\end{abstract}

\section{INTRODUCTION}

The 2010-2011 Christchurch earthquakes have highlighted the impact of soil liquefaction and associated phenomena to the built environment. A cursory review of the current state of research on soil liquefaction showed that nearly all the work on this topic has been directed towards understanding the properties of hard-grained (quartz) sands; very little research has been performed on the dynamic characteristics of volcanically-derived sands.

However, it is known that New Zealand's active geologic past has resulted in widespread deposits of volcanic soils throughout the country. The $M_{L}=6.31987$ Edgecumbe earthquake, for example, showed localised patches of liquefaction of sands of volcanic origin across the Rangitaiki Plains [1]. Pumice-rich deposits are found in several areas of the North Island, notably in the areas adjacent to the Taupo Volcanic Zone (TVZ), and their concentration in river valleys and flood plains means they tend to coincide with areas of considerable human activity and development. Thus, they are frequently encountered in engineering projects and their evaluation is a matter of considerable geotechnical interest.

Previous research by Wesley et al. [2] showed that the penetration resistance $\left(q_{c}\right)$ values obtained from cone penetration tests (CPT) on pure pumice sand were only marginally influenced by the density of the material. The reason for this behaviour is possibly because the stresses imposed by the penetrometer are so severe that particle breakage forms a new material whose properties are nearly independent of the initial state of the sand. Thus, conventional relationships between $q_{c}$ value and relative density, $D_{r}$, which in turn is correlated with cyclic resistance ratio $(C R R)$, appear to be not valid for these soils. In addition, research results reported by Orense et al. [3] and Orense and Pender [4] indicated that penetration-based approaches, such as CPT and seismic dilatometer tests, generally underestimated the $C R R$ of the pumice-rich deposits, confirming that any procedure where the liquefaction resistance is correlated with relative density will not work on these deposits. The same research showed that empirical method based on shear wave velocity $\left(V_{s}\right)$ seemed to produce good correlation with the CRR of pumiceous soils. Admittedly, the above observations were obtained from limited number of test data and such conclusions have not been wellvalidated. With many consultants and practitioners constantly asking for advice on how to evaluate the liquefaction susceptibility of pumice deposits, there is indeed a need to clarify and address this issue.

This paper presents the results of recent investigation on the evaluation of liquefaction triggering of in-situ pumice deposits through field testing at two sites where liquefaction has been observed following the 1987 Edgecumbe earthquake. Using field-derived data, attempts were made to explain the occurrence/non-occurrence of liquefaction at the target sites following the earthquake using available empirical chart-based approaches. To explain the findings, undisturbed soil samples were obtained at both sites and laboratory tests were conducted to examine the laboratory-based $C R R$ of the soils. Finally, the applicability of the current field-based empirical approaches was scrutinised vis-à-vis the laboratory-derived liquefaction characteristics of the pumice-rich sands.

\footnotetext{
1 Corresponding Author, Associate Professor, University of Auckland, Auckland, r.orense@auckland.ac.nz (Member)

2 PhD Student, University of Auckland, Auckland (Student member)

3 Lecturer, University of Canterbury, Christchurch (Member)

4 Professor of Geotechnical Engineering, University of Auckland, Auckland (Fellow)
} 


\section{SELECTED TEST SITES AND FIELD TESTING}

Two sites where liquefaction had been observed during the 1987 Edgecumbe Earthquake were selected in this research. Test site \#1 was located adjacent to the Whakatane Sewage Pump station, while Test site \#2 was opposite the Edgecumbe Power Substation (see Figure 1). The western side of the pump station underwent liquefaction-induced settlement, but only "patches" of sand ejecta were reported on the street surface along McAlister Street and Beach Road and no obvious damage to houses in the area (i.e. site \#1) [1]. While the power substation incurred damage to some of its transformers, only localised liquefaction was reported in the vicinity of Hydro Road (i.e. site \#2) [1]. Thus, it can be surmised that the severity of liquefaction at both sites were minor to moderate.

At both sites, borehole sampling, cone penetration test (CPT), seismic cone penetration test (sCPT), and screw driving sounding (SDS) were performed (see Figure 2). SDS is a new in-situ method that has recently been developed in Japan, where a rod is drilled into the ground at several loading steps at the same time as the rod is being continuously rotated. Details of this test are reported elsewhere [5]. The SDS test is fast, the machine is small and portable and the implementation is relatively cheap, compared to other in-situ testing methods.

Boreholes from the two tests sites indicate the presence of fine to coarse sand layers intermittently mixed with pumice. At Site \#1, the presence of pumice sands were visible between $0.5-7 \mathrm{~m}$, while at Site \#2, pumice was mixed with fine to medium sand from 0.5-6.2 m. The ground water table was located at about 2 $\mathrm{m}$ from the surface at both sites.

The results of the field tests are shown in Figures 3 and 4 for Site \#1 and Site \#2, respectively. At Site \#1, the cone tip resistance was about $q_{c}=4 \mathrm{MPa}$ up to a depth of $5 \mathrm{~m}$ and it increased to about $q_{c}=8 \mathrm{MPa}$ up to a depth of $10 \mathrm{~m}$. The soil behaviour type (SBT), derived from CPT data, indicated alternating layers of sand and silt mixtures up to a depth of $5 \mathrm{~m}$, and predominantly sand up to a depth of $12 \mathrm{~m}$. The shear wave velocity profile showed $V_{s}$ ranging from $90-120 \mathrm{~m} / \mathrm{s}$ up to a depth of $5 \mathrm{~m}$, after which $V_{s}$ increased with depth, reaching 170 $\mathrm{m} / \mathrm{s}$ at depth of $11 \mathrm{~m}$. During the SDS test, several parameters were measured every $25 \mathrm{~cm}$; these include torque, load, speed of penetration, depth of penetration and friction on the rod. An important parameter derived from the measured data is the specific energy of penetration, $E_{s}$, representing the sum of the contribution of the torque and applied load for every load step normalised by the volume of penetration [6]. At Site \#1, $E_{s}<25$ $\mathrm{N} \cdot \mathrm{mm} / \mathrm{mm}^{3}$ up to a depth of $10 \mathrm{~m}$, below which stiff layer with $E_{s}<50 \mathrm{~N} \cdot \mathrm{mm} / \mathrm{mm}^{3}$ existed.

At Site \#2, $q_{c}$ was generally $<8 \mathrm{MPa}$, except at depths of 3.0$3.5 \mathrm{~m}$ and $>6.5 \mathrm{~m} ; V_{s}$ generally varied between $110-170 \mathrm{~m} / \mathrm{s}$. SDS indicated $E_{s}<30 \mathrm{~N} \cdot \mathrm{mm} / \mathrm{mm}^{3}$, except at depths of 3.0-3.5 $\mathrm{m}$ and $>6.5 \mathrm{~m}$. From all tests, a hard layer was apparent at depth of approximately $7 \mathrm{~m}$, where $q_{c}>20 \mathrm{MPa}, V_{s}>160 \mathrm{~m} / \mathrm{s}$, and $E_{s}>70 \mathrm{~N} \cdot \mathrm{mm} / \mathrm{mm}^{3}$; thus, tests at this site were terminated at this depth.

\section{EVALUATION OF LIQUEFACTION TRIGGERING}

For the purpose of evaluating the liquefaction triggering at both sites during the Edgecumbe earthquake, six simplified empirical methods were employed: 3 CPT-based methods - i.e. those proposed by Boulanger and Idriss [7], Robertson and Cabal [8] and Moss et al. [9]; two $V_{s}$-based methods - i.e. those proposed by Andrus and Stokoe [10] and Kayen et al. [11]; and the SDS-based method proposed by Mirjafari et al. [6]. To estimate the peak ground accelerations (PGA) in Whakatane following the Edgecumbe earthquake with moment magnitude $M_{W}=6.5$, Mellsop [12] developed ground motion intensity models through modification of ground motion prediction equations to fit the strong motion recordings in the wider region. Based on the results, the lower and mean PGA estimates for site \#1 were $0.17 \mathrm{~g}$ and $0.29 \mathrm{~g}$, while the median PGA for site

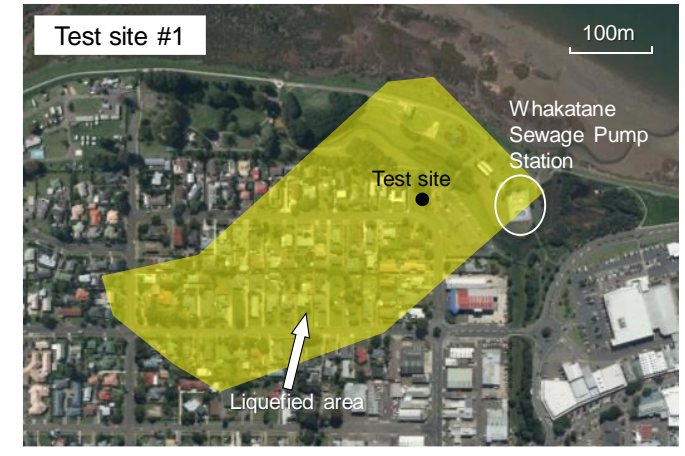

(a)

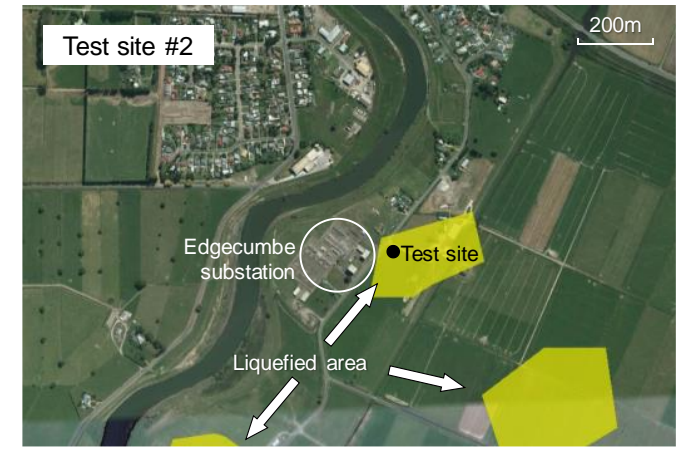

(b)

Figure 1: Target sites for the study: (a) Test site \#1 near Whakatane Sewage Pump station; and (b) Test site \#2 near Edgecumbe substation. Yellow hatched zones are the regions where liquefaction had been observed based on literature.

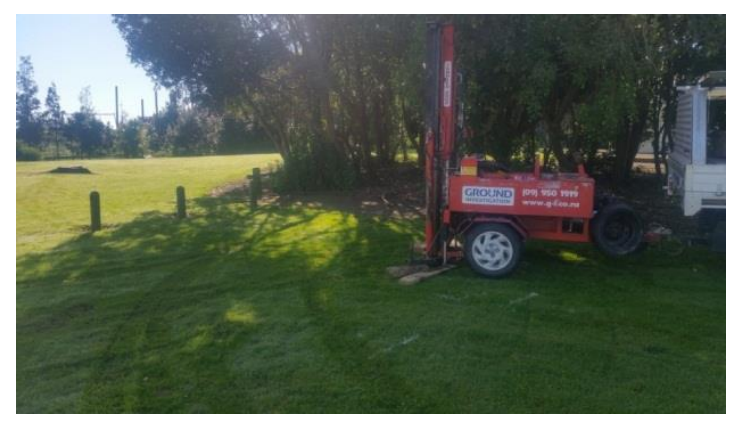

(a)

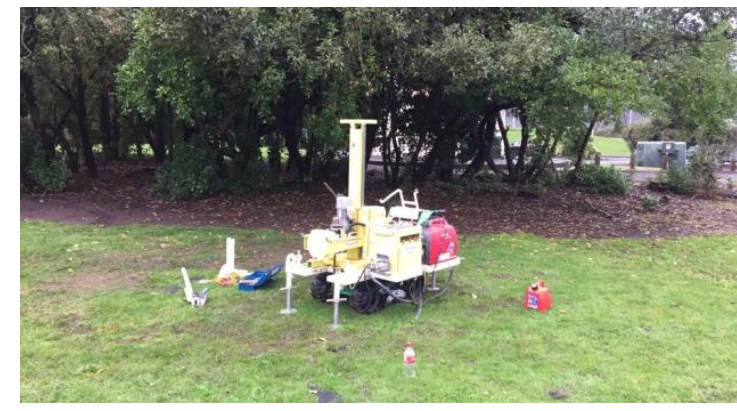

(b)

Figure 2: Field testing at Target site \#1: (a) CPT and SCPT; and (b) SDS test. 


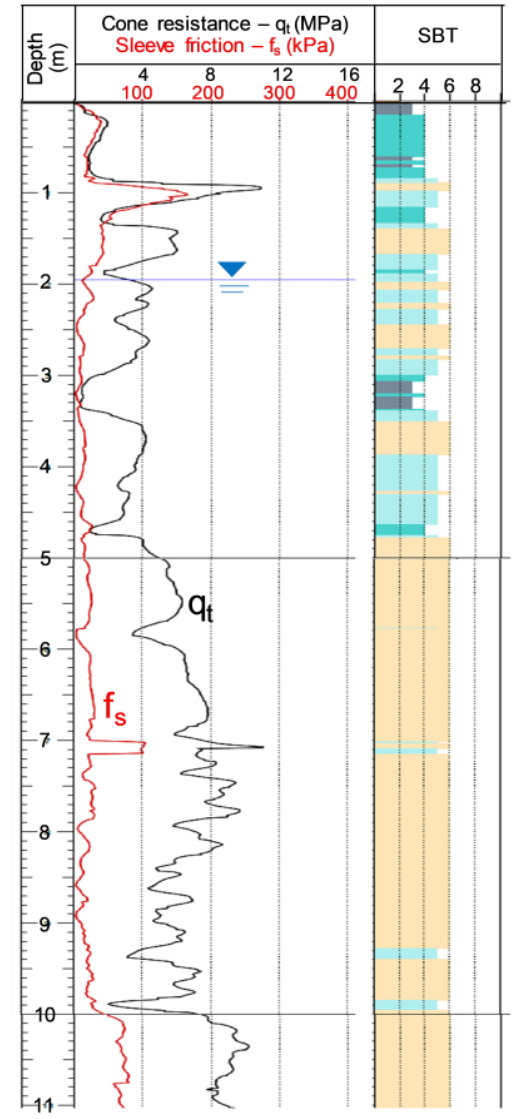

(a) CPT profile

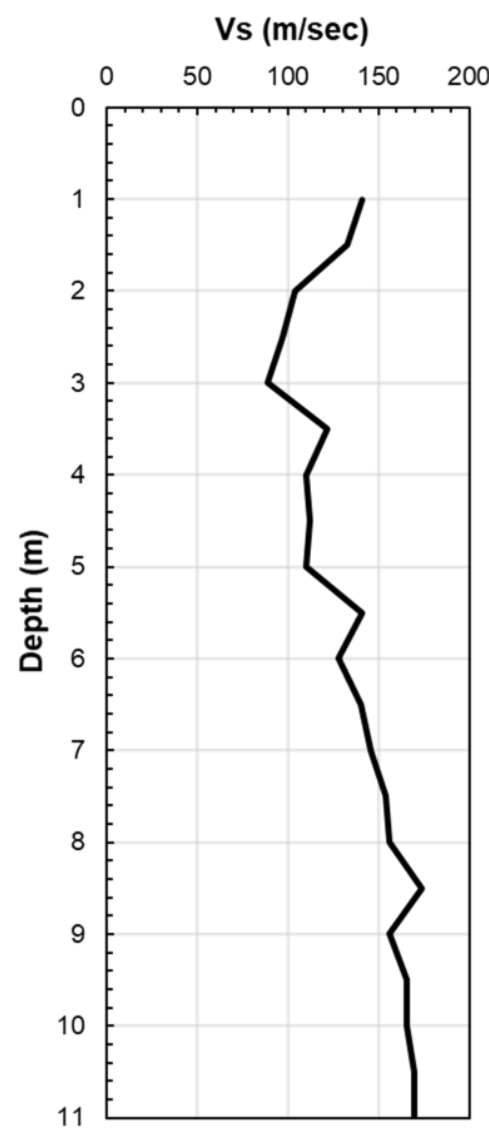

(b) Vs-profile

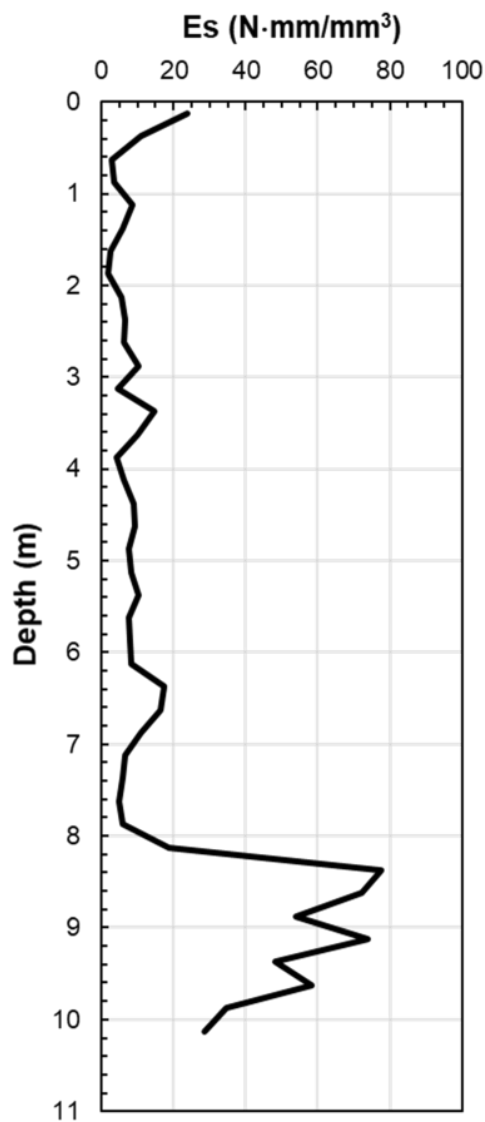

(c) SDS Energy profile

Figure 3: Results of field testing at Site \#1.

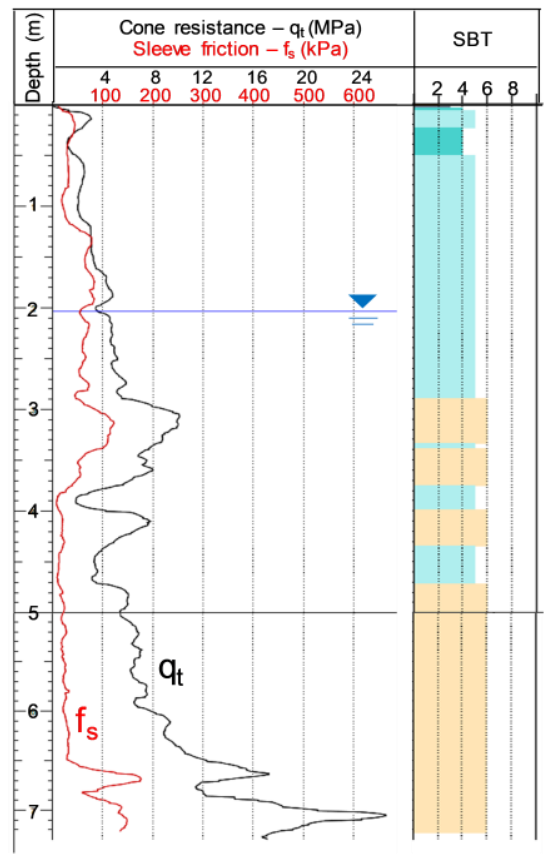

(a) CPT profile

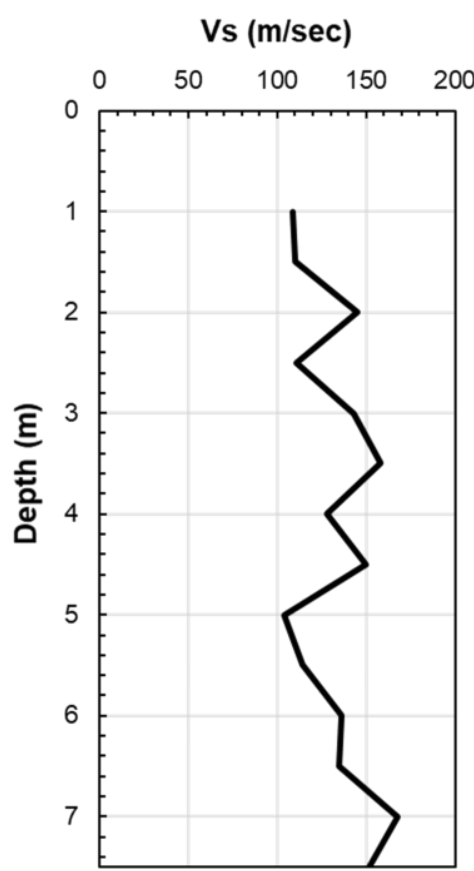

(b) Vs-profile
Es $\left(\mathrm{N} \cdot \mathrm{mm} / \mathrm{mm}^{3}\right)$

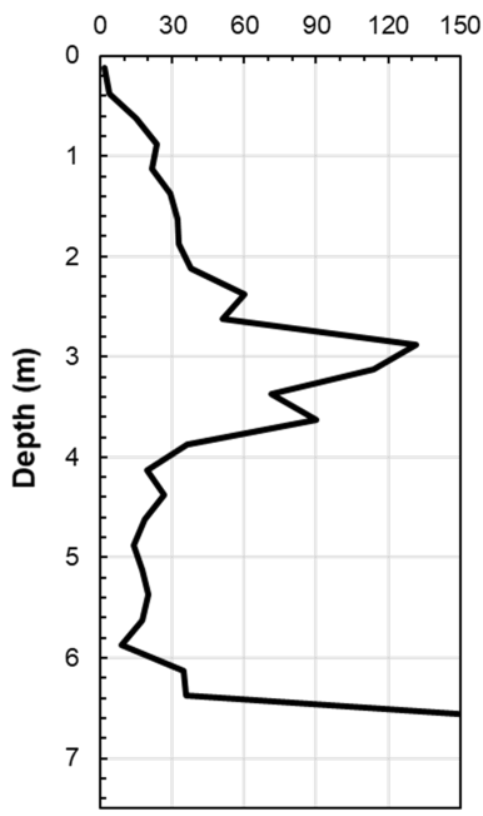

(c) SDS Energy profile

Figure 4: Results of field testing at Site \#2. 

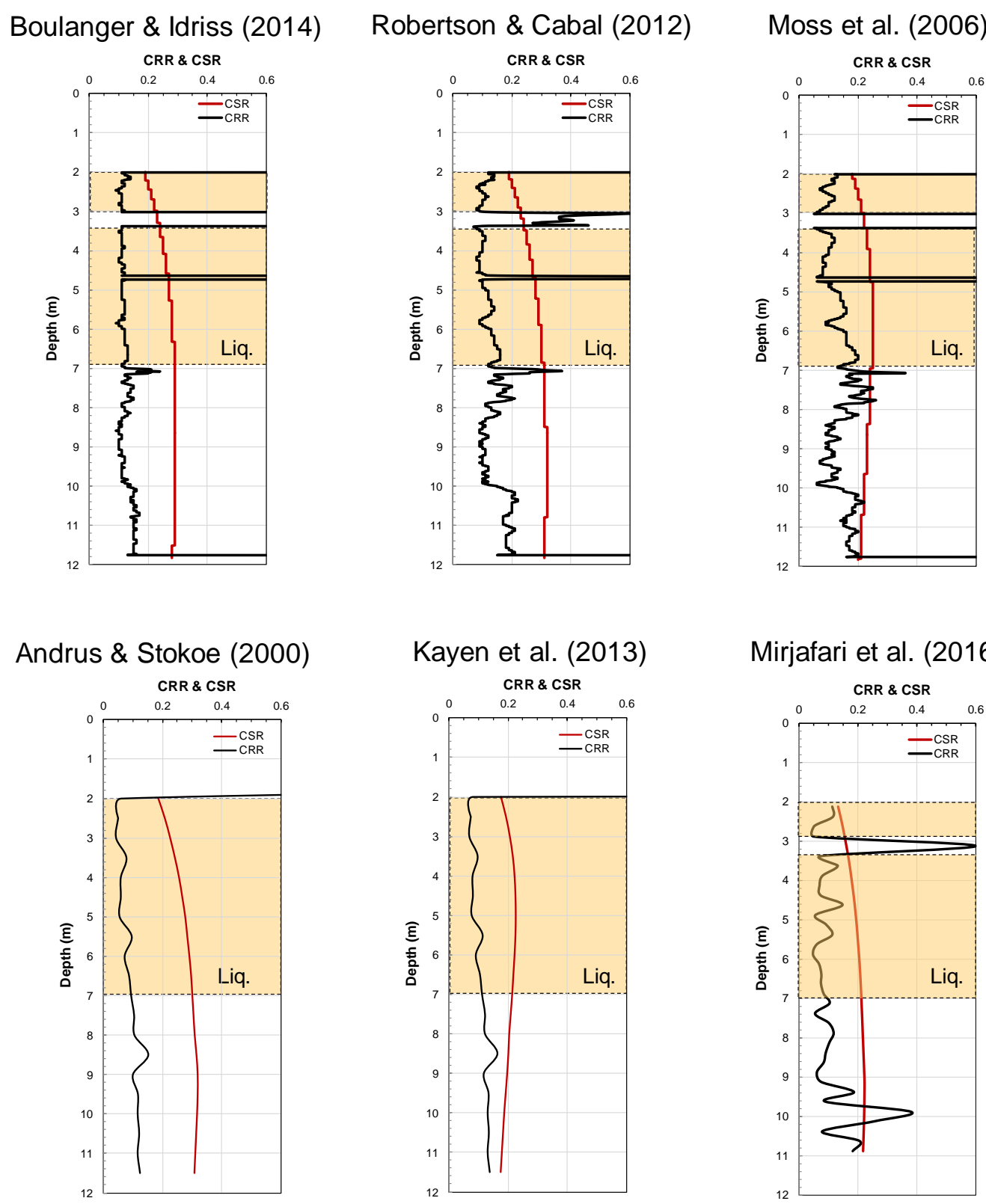

Mirjafari et al. (2016)

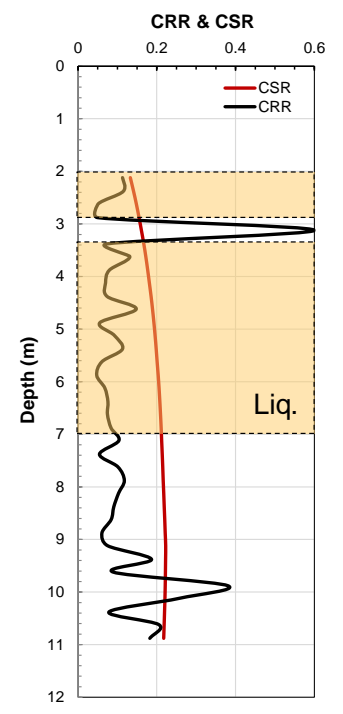

Figure 5: Liquefaction triggering results for Site \#1, with GWT=2.0m.

\#2 was 0.53g (N. Mellsop, personal communication, 5 September 2016). The median values were used in this study.

In terms of ground water table (GWT), Pender \& Robertson [1] reported the following: "the earthquake occurred at the end of the summer and after a long period of dry weather. Most of the deposits underlying the Rangitaiki Plains are saturated, with the water table ranging from near surface in the coastal margin, to about $3 \mathrm{~m}$ below ground level in the Te Teko area.

(In Edgecumbe), the top of the soil profile is a layer of about $3 m$ thickness which is very loose, (and) at the time of the earthquake, the water table was probably towards the bottom of this layer over much of the plains." Thus, for the purpose of the analyses, the GWT location was assumed at: $1 \mathrm{~m}, 2 \mathrm{~m}$ and $3 \mathrm{~m}$ from the ground surface for Site \#1, and $2 \mathrm{~m}, 3 \mathrm{~m}$ and $4 \mathrm{~m}$ for Site \#2.

Considering the input parameters mentioned above, liquefaction assessment was conducted using the six simplified methods. Results for Site \#1 considering GWT=2 m are shown in Figure 5, while Figure 6 illustrates the results for Site \#2 with $\mathrm{GWT}=3 \mathrm{~m}$. In the figures, the depth profile of the cyclic stress ratio $(C S R)$ and cyclic resistance ratio $(C R R)$ are plotted, and the shaded regions represent the pumice-rich zones which are deemed to have liquefied (i.e. $C R R<C S R$ ).

Based on the results, it is clear that at Site \#1 where field testing has been done up to a depth of $11.5 \mathrm{~m}$, all the methods considered would predict liquefaction of the pumice-rich deposits (between the depth ranging from the location of the water table up to $7 \mathrm{~m}$ depth). Similarly, at Site \#2, all methods would predict pumice layer liquefaction between GWT up to 7 $\mathrm{m}$ depth. Similar results were obtained for the other GWT locations investigated. Thus, it would appear that for the sites selected, all empirical methods were able to predict the occurrence of liquefaction of the pumice layers.

However, from the results of the analyses, it is observed that for both sites, the calculated factor of safety, $F o S \approx 0.3 \sim 0.5$; expressed in terms of indices for liquefaction-induced damage, such as the post liquefaction settlement, $\Delta s$, Liquefaction Potential Index, LPI [13] or Liquefaction Severity Number, $L S N$ [14], the low FoS would have resulted in severe manifestations of liquefaction, such as extensive sand boils, 

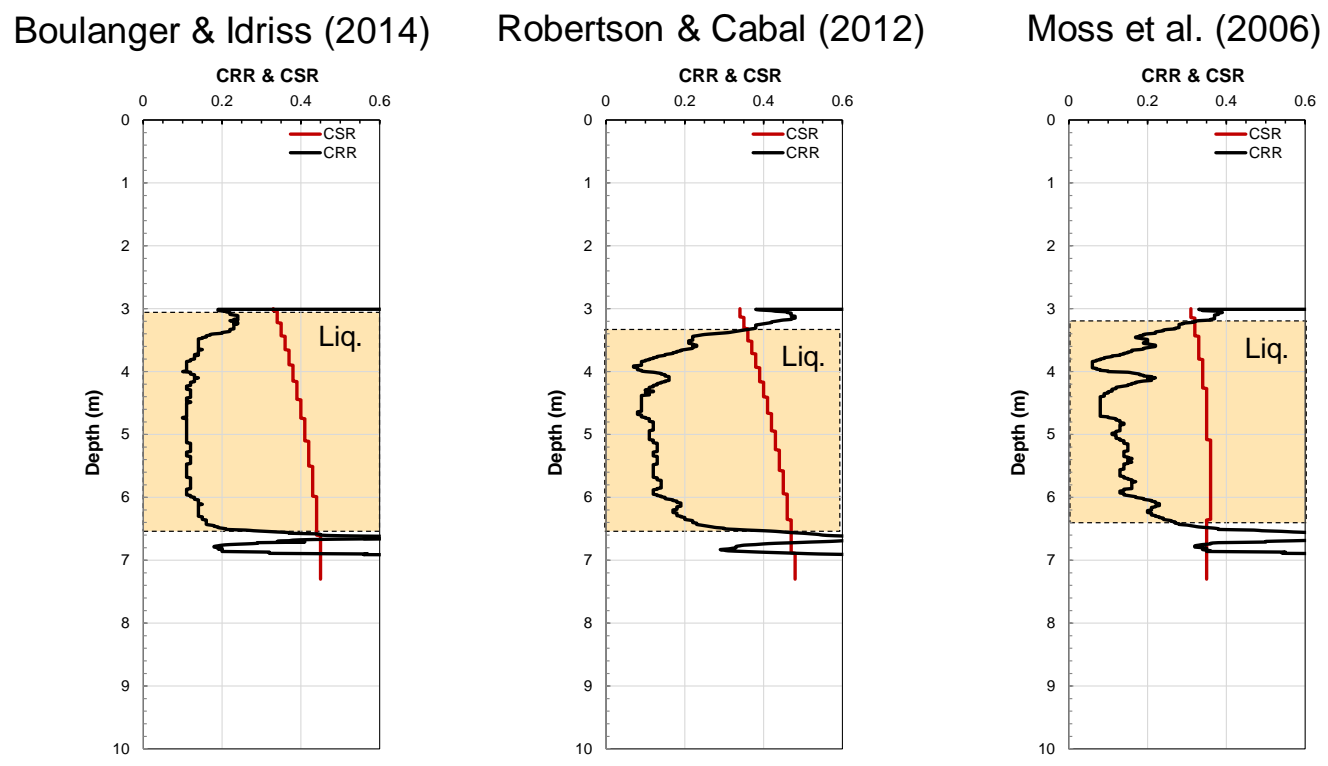

\section{Andrus \& Stokoe (2000)}
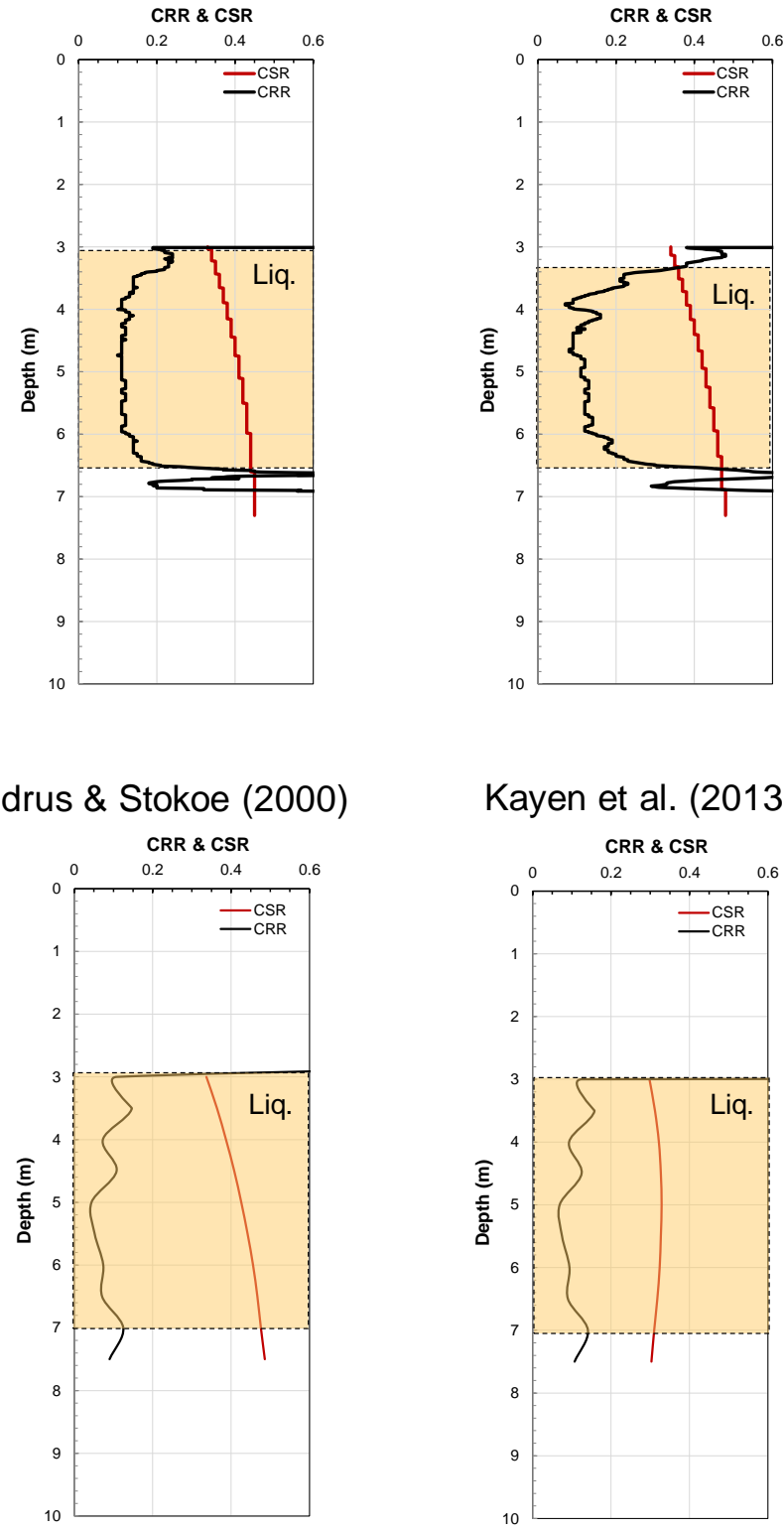

Kayen et al. (2013)

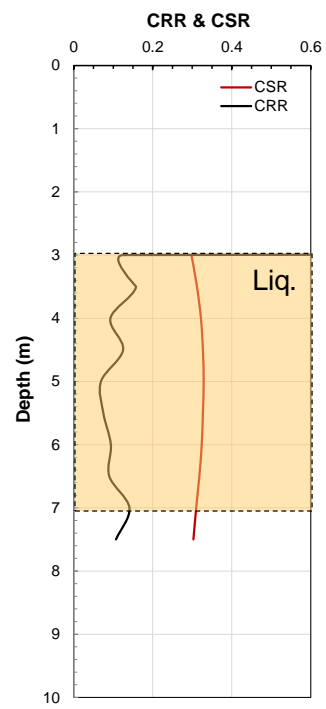

Mirjafari et al. (2016)

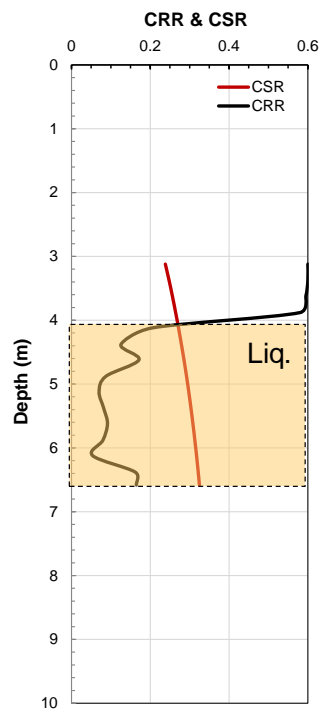

Figure 6: Liquefaction triggering results for Site \#2, with GWT=3.0m.

ground cracks and settlement (for Site \#1, $L P I=28 \sim 32$, $\Delta s=35 \sim 40 \mathrm{~cm}$; for Site \#2, $L P I=15 \sim 20, \Delta s=10 \sim 16 \mathrm{~cm}$ for the indicated GWT), However, per the available literature review, only minor to moderate damage, in the form of localised sand boils, were observed at both sites.

The discrepancy between the estimated damage and observed manifestation of liquefaction may be due to the following factors: (1) the CSR induced by the earthquake, manifested by the PGA used, may be quite high; and (2) the $C R R$, estimated using field-based parameters may have significantly underestimated the actual liquefaction resistance of the pumicerich soils. Considering that the PGA values used are consistent with the overall work reported by Mellsop [14], a logical conclusion would be that the CRR used is substantially underestimated. Hence, research efforts were shifted to the determination of the cyclic resistance of the in-situ sands.

\section{UNDISTURBED SAMPLING AND LABORATORY TESTING}

In order to clarify the issue and as part of a broader research to understand the behaviour of pumice-rich sands, undisturbed samples were obtained from both sites (see Figure 7). At Site \#1 (see Figure 8), soil samples at various depths were recovered using a total of four different techniques: conventional push tubes (PT) with $76 \mathrm{~mm}$ diameter (max sample length, $L_{s, \max }=$ $50 \mathrm{~cm}$ ); Dames \& Moore (DM) hydraulically-activated fixed piston sampler with thin-walled brass tubes $\left(L_{s, \max }=45 \mathrm{~cm}\right.$, diameter = $61 \mathrm{~mm})$; Gel-push "static" (GP-S) hydraulicallyactivated fixed piston sampler $\left(L_{s, \max }=92 \mathrm{~cm}\right.$, diameter $=70$ $\mathrm{mm})$; and Gel-push "triple tube" (GP-TR) core barrel. $\left(L_{s, \max }=\right.$ $100 \mathrm{~cm}$, diameter $=83 \mathrm{~mm}$ ). Based on the experience from Site \#1, only the Gel-push "triple tube" (GP-TR) was employed at Site \#2 (see Figure 9).

It is worth mentioning that gel-push sampling is an emerging technique that has been developed by Kiso-Jiban Consultants in 

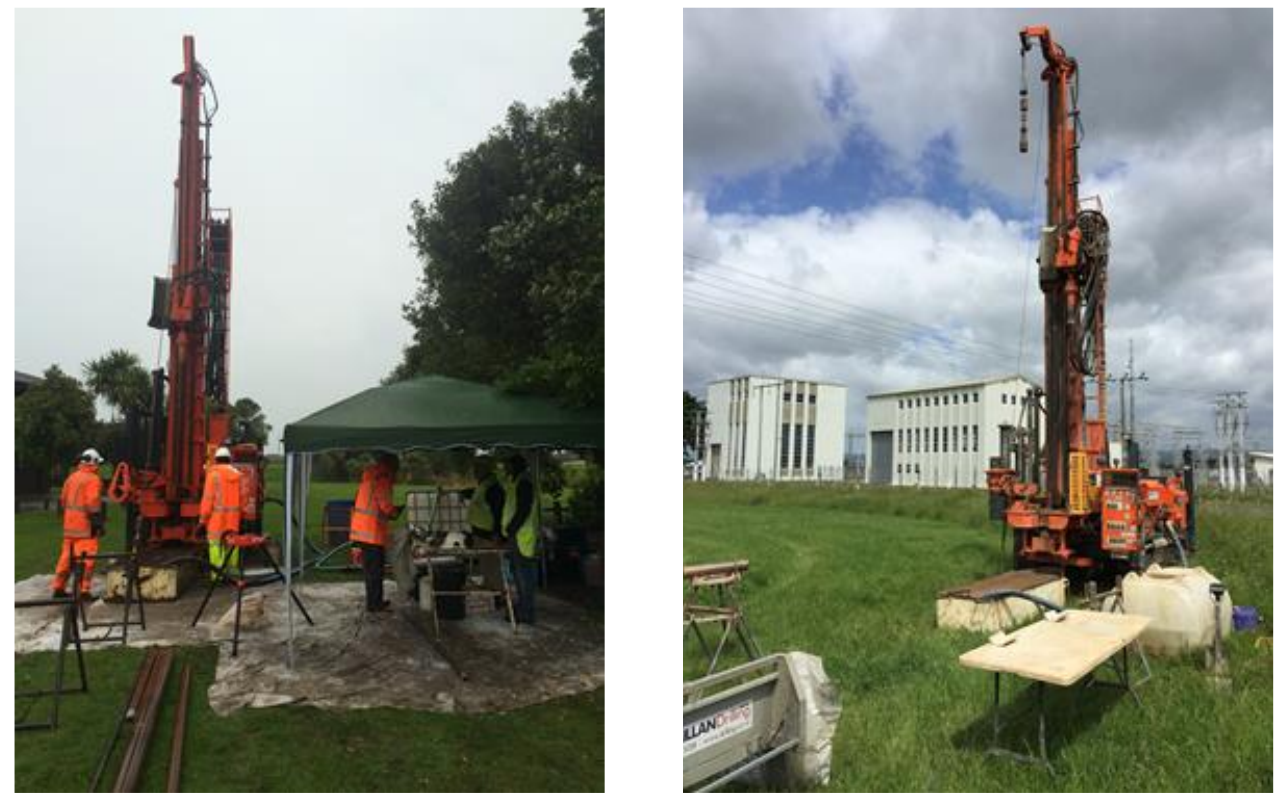

Figure 7: Sampling condition at: (a) Site \#1; and (b) Site \#2.

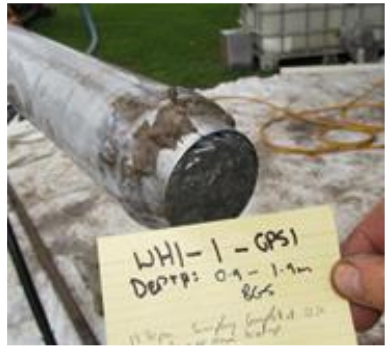

(a) from GP-S sampler

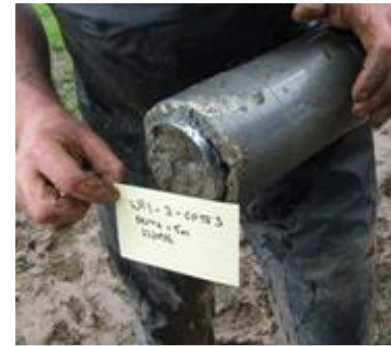

(b) from GP-TR sampler

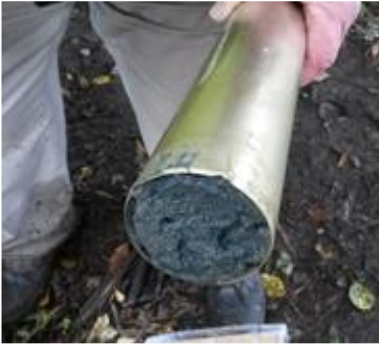

(c) from DM sampler

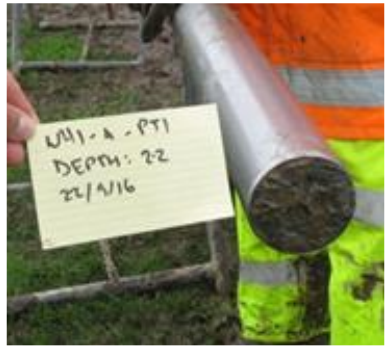

(d) from push tube

Figure 8: Typical on-site samples obtained at Site \#1 using different samplers.

Japan. The two gel-push samplers used in this study are similar to the modified Osterberg sampler and the Mazier core barrel. In both cases, samples are captured within a core liner barrel, and the key innovation is the introduction of a lubricating polymer gel, which coats the outside surfaces of soil samples as they enter into the tools and can eliminate sidewall friction [15]. On the other hand, the DM sampler is an Osterberg-type sampling device that uses thin-walled, constant inside-diameter brass sample tubes with an outside cutting edge bevel of $60^{\circ}$ to reduce disturbance during sampling. Further details of the sampling conditions and issues encountered at Site \#1 are discussed by Stringer et al. [16].

When the samples were brought to the surface, a preliminary assessment of visual and tactile quality was undertaken at the two ends of the samples. It is assumed that the top and bottom of the sample will likely represent the poorest quality of the particular soil sample since these remain directly exposed within the borehole after sampling and have experienced the effects of the rotary drilling (at the top of the sample) and suction pressures as the sample is lifted from the ground. In this project, visual quality in the field is assessed by the overall appearance of the sample, including the sample tube (note the denting of the brass DM sample tube in Figure 8c). The tactile quality of the specimens represents whether the soil at either end of the sample felt firm to a finger touch. In samples where poor tactile quality was noted, then the samples will typically have been very soft, or (in the case of the top of the sample tube), they might have been liquefied (i.e. slurry) to some depth. In these cases, it is thought that the soils have undergone
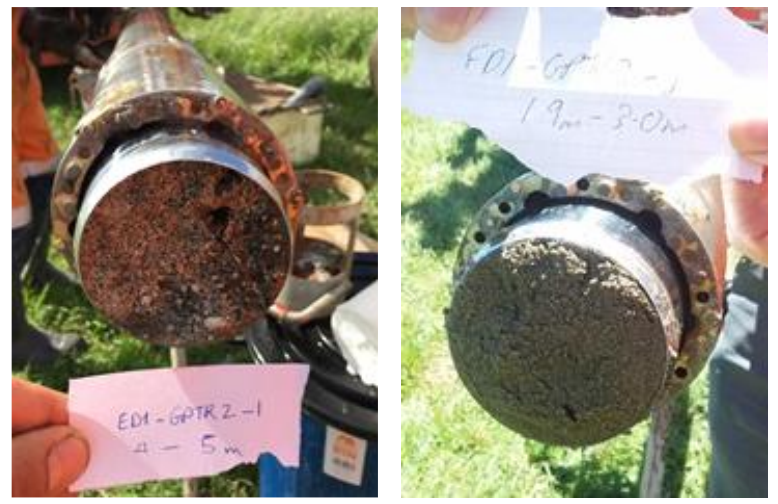

Figure 9: Typical on-site samples obtained at Site \#2 using the GP-TR sampler.

significant disturbance to cause the softening. In the case of the gel-push samples, the sampler must be laid out horizontally after being recovered from the hole. For these samples, the highest quality reflects the situation where the sample is both firm to the touch, and can be moved within the tube using finger pressure, which indicates that the gel has correctly coated the sample.

Once the samples have been transported to the laboratory a second visual inspection is performed to verify that there are no obvious features on the exterior of the specimen that suggest poor quality (e.g. cracks on the specimen). 
Table 1: Sample quality, material composition and pumice content of samples obtained at both sites.

(a) Site \#1 (Whakatane)

\begin{tabular}{|c|c|c|c|c|c|}
\hline Sample & Depth (m) & Recovery (cm) & Quality & Material & Pumice Content \\
\hline WH1-1-GPS1 & 0.9 & $90(98 \%)$ & Good & Silty sand & Low \\
\hline WH1-1-GPS2 & 2.15 & $88(96 \%)$ & Good & Medium sand & Low \\
\hline WH1-1-GPS3 & 3.65 & 87 (95\%) & $\begin{array}{l}\text { Medium/Poor (soft at } \\
\text { base, some visual } \\
\text { settlement) }\end{array}$ & Medium to coarse sand & Low \\
\hline WH1-1-GPS4 & 4.95 & $32(35 \%)$ & Poor (visually poor) & Coarse sand & Medium \\
\hline WH1-2-DM1 & 1.35 & $45(100 \%)$ & Good & Silty sand & Low \\
\hline WH1-2-DM2 & 2.6 & $45(100 \%)$ & $\begin{array}{l}\text { Top: Sampler dented } \\
\text { Bottom: Firm }\end{array}$ & Fine to coarse sand & Low \\
\hline WH1-2-DM3 & 3.4 & $32.4(72 \%)$ & $\begin{array}{l}\text { Top: Sampler dented } \\
\text { Bottom: Firm }\end{array}$ & Fine to coarse sand & Medium \\
\hline WH1-2-DM4 & 4.2 & $37(82 \%)$ & Good & Medium to coarse sand & High \\
\hline WH1-2-GPS5 & 5.0 & $30(33 \%)$ & $\begin{array}{l}\text { Poor (visually poor, } \\
\text { and slurry at top end) }\end{array}$ & Coarse sand & High \\
\hline WH1-3-GPS1 & 2.2 & 85 (92\%) & Good & Fine sand & Low \\
\hline WH1-3-GPTR2 & 3.7 & 69 (69\%) & Good & Medium-Coarse sand & High \\
\hline WH1-3-GPTR3 & 5.0 & 91 (91\%) & Good & Medium sand & Medium \\
\hline WH1-4-PT1 & 2.2 & $55(110 \%)$ & $\begin{array}{l}\text { Poor (top was slurry, } \\
\text { bottom firm) }\end{array}$ & Fine sand & Low \\
\hline WH1-4-PT2 & 3.7 & 48.5 (97\%) & $\begin{array}{l}\text { Poor (top was slurry, } \\
\text { bottom firm) }\end{array}$ & Coarse sand & Medium \\
\hline WH1-4-PT3 & 5.0 & $54(108 \%)$ & $\begin{array}{l}\text { Poor (top was slurry, } \\
\text { bottom firm) }\end{array}$ & Coarse sand & High \\
\hline
\end{tabular}

(b) Site \#2 (Edgecumbe)

\begin{tabular}{|c|c|c|c|c|c|}
\hline Sample & Depth (m) & Recovery (cm) & Quality & Material & Pumice Content \\
\hline ED1-1-GPTR1 & 2.9 & $100(100 \%)$ & $\begin{array}{l}\text { Top: poor (slurry); } \\
\text { Bottom: good }\end{array}$ & Fine sand & Medium \\
\hline ED1-1-GPTR2 & 4.0 & $88(88 \%)$ & Good & $\begin{array}{l}\text { Top: Silty gravel } \\
\text { Bottom: Sandy gravel }\end{array}$ & Medium \\
\hline ED1-1-GPTR3 & 5.2 & $0 \dagger$ & $\mathrm{N} / \mathrm{A}$ & Medium coarse sand & Medium \\
\hline ED1-1-GPTR4 & 5.45 & 94 (94\%) & Good & $\begin{array}{l}\text { Top: Sandy gravel } \\
\text { Bottom: Gravelly sand }\end{array}$ & $\begin{array}{l}\text { Top: Medium } \\
\text { Bottom: Low }\end{array}$ \\
\hline ED1-2-GPTR1 & 2.6 & $100(100 \%)$ & Good & Fine sand & Medium-high \\
\hline ED1-2-GPTR2 & 4.0 & $52.5(53 \%)$ & Good & $\begin{array}{l}\text { Coarse sand to medium } \\
\text { gravel }\end{array}$ & High \\
\hline ED1-2-GPTR3 & 5.5 & $70(70 \%)$ & $\begin{array}{l}\text { Medium (sample } \\
\text { dropped out during } \\
\text { recovery) }\end{array}$ & Sandy gravel & Medium/High \\
\hline ED1-3-GPTR1 & 1.9 & $100(100 \%)$ & Good & Fine sand & High \\
\hline
\end{tabular}

† unable to advance the sampler through hard horizon.

A summary of the sample quality, material composition and inferred pumice contents from ocular inspection is presented in Table 1. Note that the samples are referred to by a three part naming convention, indicating the site (WH1 for site \#1 or ED1 for site \#2), the borehole number (e.g. 1, 2,3), and finally the tool used to obtain the sample and the sample number within the borehole (e.g. GPTR1 indicates that the sample was obtained using the gel-push triple tube sampler, and was the first sample obtained from that borehole). It is also worthy to note that while the boreholes were placed approximately $2 \mathrm{~m}$ apart, the samples obtained at practically the same depth varied significantly in visual appearance (material characteristics and pumice contents), possibly as a result of the alluvial deposition environment.

Notwithstanding the possibility that improvements to the DM sampling procedures may provide samples of high quality, it is through that the GP sampling provided the best samples at site \#1. Further details of the sampling conditions and issues encountered at site \#1 are discussed by Stringer et al. [16]. At site \#2, samples were obtained using the GP-Tr sampler only and targeted depths up to $7 \mathrm{~m}$. Sample quality at site \#2 was generally good with a few exceptions, as noted in Table 1.

After recovery, the soil samples were drained on site and then uniaxially frozen using dry ice before transportation to the laboratories at the Universities of Auckland and Canterbury. The sampling tubes were stored in a freezer until they were ready for testing. At the University of Auckland, the cyclic triaxial tests were conducted on specimens of about $63 \mathrm{~mm}$ in diameter and $126 \mathrm{~mm}$ in height; hence, the gel-push and push tube specimens had to be trimmed (while thawing a bit from its frozen state) to reduce the diameter. After trimming the soil specimens, the structure of the soil was visible and had clearly been well-preserved by the sampling. Stringer et al. [17] discussed some of the inherent problems associated with testing undisturbed pumice-rich samples, including visible layering and uneven distribution of pumice contents within the sample. After thawing followed by saturation (with $B$-value $>0.95$ ) and consolidation (under isotropic condition at effective confining pressure of $\sigma_{c}{ }_{c}=100 \mathrm{kPa}$ ), the samples were cyclically sheared under undrained condition at frequency of $0.1 \mathrm{~Hz}$.

The results of the undrained cyclic triaxial tests were then summarised in the form of liquefaction resistance curves, defined in terms of the number of cycles required to obtain double amplitude axial strain of $\varepsilon_{D A}=5 \%$. The curves for some of the samples obtained at sites \#1 and \#2 are shown in Figure 10. It is noted that there is scatter in the data points, an indication that within the samples obtained over a certain depth (generally depth interval of about $0.5 \mathrm{~m}$ ) or within the $126 \mathrm{~mm}$ high specimen itself, the samples were non-homogenous. Bands consisting of high pumice contents appear in between layers of low pumice contents, such as those shown in Figure 11; such inhomogeneity of the samples can result in notably different response when compared to other samples of adjacent depth. 


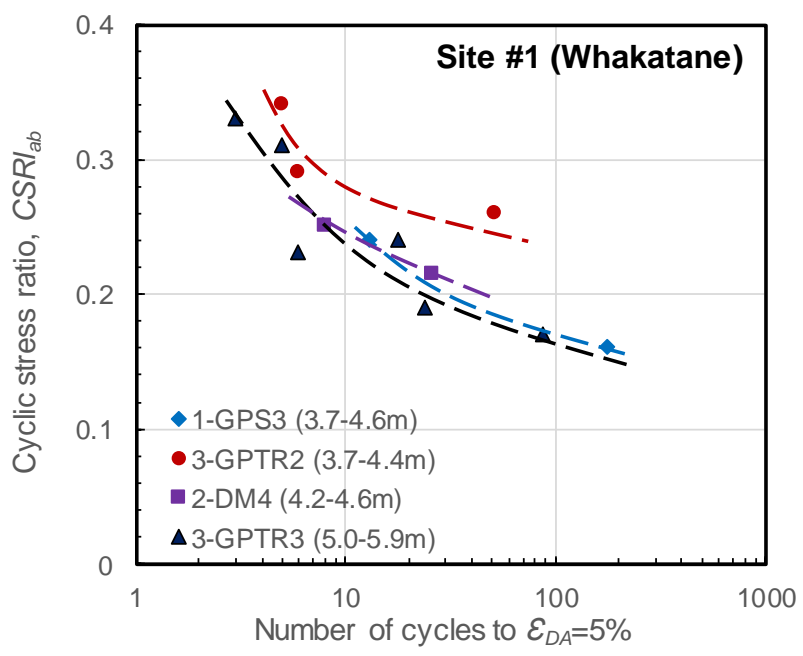

(a) Site \#1 samples

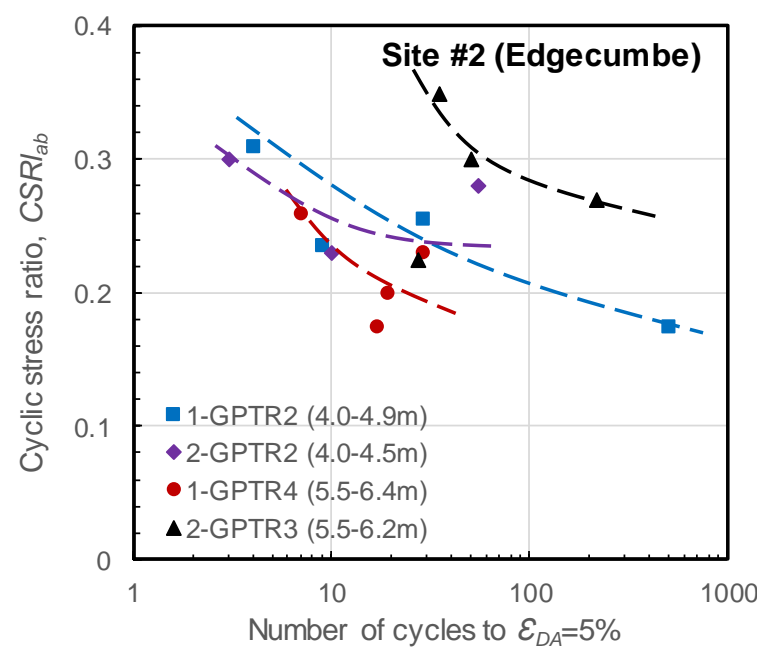

(b) Site \#2 samples

Figure 10: Liquefaction resistance curves for the undisturbed samples. The samples are designated by the sampler type, borehole number and sample number, and the depths where the samples were retrieved are indicated in the parenthesis.

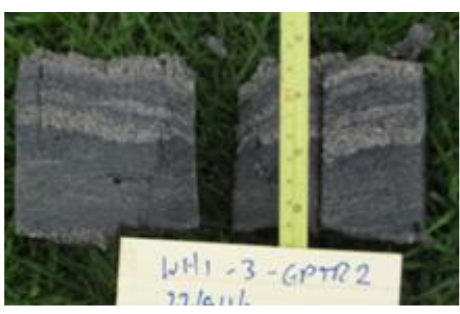

(a)

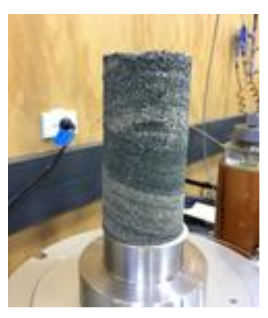

(b)
Figure 11: Visible layering of the pumice-rich samples: (a) on-site samples; and (b) laboratory specimens. Pumice sands are characterised by their yellow-brown colour.

For example, in Figure 10(b) the two sets of samples taken from depth of about 5.5-6.2 m show remarkable difference in liquefaction resistance. This is due to the difference in pumice contents, particle size distributions (especially the size of pumice particles within the soil matrix) and soil structure. Bender element testing showed that the two sets of samples have different shear wave velocities too.

In view of the typical number of significant cycles present in many time histories of accelerations recorded during past earthquakes, it is customary to consider 15 cycles of loading, representing $M_{w}=7.5$ earthquake, to estimate the liquefaction resistance (or cyclic strength) of the soil; herein, this is referred to as $(C R R)_{l a b}=\left(\sigma_{d}^{\prime} / 2 \sigma_{c}^{\prime}\right)$. However, the conditions the laboratory specimens were subjected to are different from those in-situ. Hence, in order to estimate the in-situ liquefaction resistance, $(C R R)_{\text {field }}=\tau_{\text {cyclic }} / \sigma_{v}^{\prime}$, corrections need to be applied to the laboratory-obtained values, as follows:

$$
\begin{aligned}
& (C R R)_{\text {field }}=\left(\frac{\tau_{\text {cyclic }}}{\sigma^{\prime}{ }_{v}}\right)_{\text {field }}=0.65\left(\frac{\tau_{\text {max }}}{\sigma^{\prime} v}\right)_{\text {field }} \\
& \left(\frac{\tau_{\text {max }}}{\sigma^{\prime}{ }_{v}}\right)_{\text {field }}=C_{1} \cdot C_{2} \cdot C_{3} \cdot C_{4} \cdot C_{5} \cdot(C R R)_{\text {lab }}
\end{aligned}
$$

where the correction factors are [18-19]:

$C_{1}$ - correction due to difference in consolidation stress. $C_{1}=\left(1+2 K_{0}\right) / 3$ where $K_{0}$ is the coefficient of lateral earth pressure at rest;

$C_{2}$ - correction due to difference in loading condition, where earthquake loading is irregular while laboratory specimens are subjected to sinusoidal waves. Generally, $C_{2}=1 / 0.65$ or $(=1 / 0.55-0.70)$;
$C_{3}$ - correction due to sample disturbance. $C_{3}>1$, but not clearly understood yet;

$C_{4}-$ correction due to densification during handling. $C_{4}<1$, but not clearly understood yet;

$C_{5}$ - correction due to loading direction, where earthquake loading is at least two components, E-W and N-S. $C_{5}=0.80-0.90$.

For normally consolidated pumice-rich soils, a value $K_{0}=0.4$ can be assumed due to their high friction angle [3]; therefore, $C_{1}=(1+2 \times 0.4) / 3=0.60$. Moreover, C $3 \cdot C 4 \approx 1$ is assumed, since the "undisturbed" samples obtained were generally of highquality as a result of various refinements on the sampling procedures and knowing which method works better for the target type of soils [19]. By further assuming $C_{5}=0.90$, it follows that

$$
\begin{aligned}
(C R R)_{\text {field }} & \approx 0.65 \cdot 0.60 \cdot\left(\frac{1}{0.65}\right) \cdot 0.9 \cdot(C R R)_{l a b} \\
& \approx 0.54 \cdot(C R R)_{l a b}
\end{aligned}
$$

Thus, in the liquefaction potential evaluation adopted herein, the in-situ cyclic resistance ratio of the pumice-rich soils can be taken as $54 \%$ of the laboratory-derived cyclic resistance.

Using the above procedure, the $(C R R)$ lab corresponding to 15 cycles from all the undrained cyclic triaxial tests conducted on samples from Site \#1 and Site \#2 are collated and correlated to the average value of the field parameters measured at the specified depths where the samples were obtained. These are then plotted in the empirical charts, as shown in Figure 12. In the figure, the CPT-based chart is that proposed by Boulanger and Idriss [7], while the $\mathrm{V}_{\mathrm{s}}$-based chart and SDS-based chart are from the procedure proposed by Kayen et al. [11] and Mirjafari et al. [6]. Note that all the charts are for clean sands (fines content $F C<5 \%$ ) and correspond to $M_{w}=7.5$ earthquake and $\sigma_{v}^{\prime}=1 \mathrm{~atm}(=100 \mathrm{kPa})$. Note that while CPT was conducted at every $10 \mathrm{~cm}$ interval, $V_{s}$-profiling and SDS were performed at interval of $50 \mathrm{~cm}$ and $25 \mathrm{~cm}$, respectively; hence, some averaging had to be done to estimate the appropriate values.

It can be observed from the figure that all the three field-based methods generally underestimate the liquefaction resistance of the pumice-rich deposits. While penetration-based methods, such as CPT (Figure 12a) and SDS (Figure 12c), are expected to provide underestimation due to particle crushing when the rods penetrate into the pumice-rich layer, even the $V_{s}$-based approach (Figure 12b) also underestimated the $C R R$. 


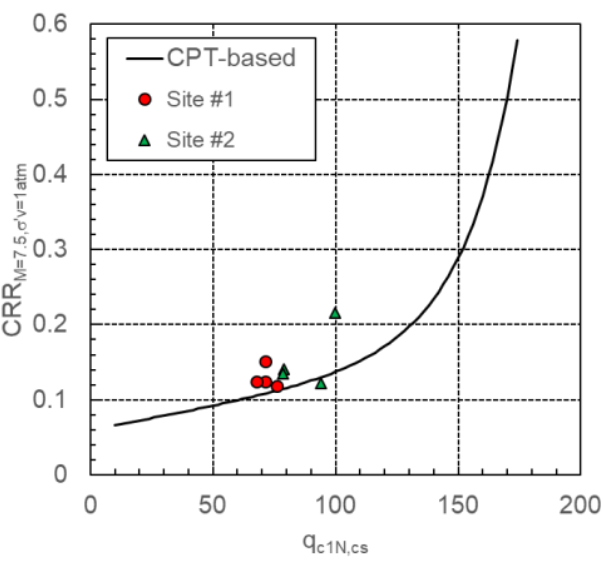

(a)

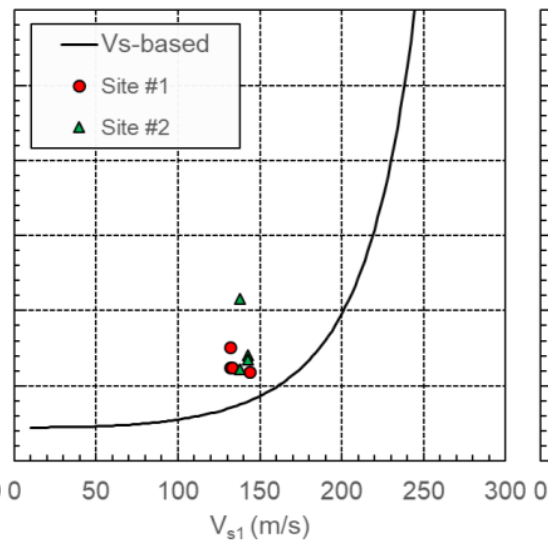

(b)

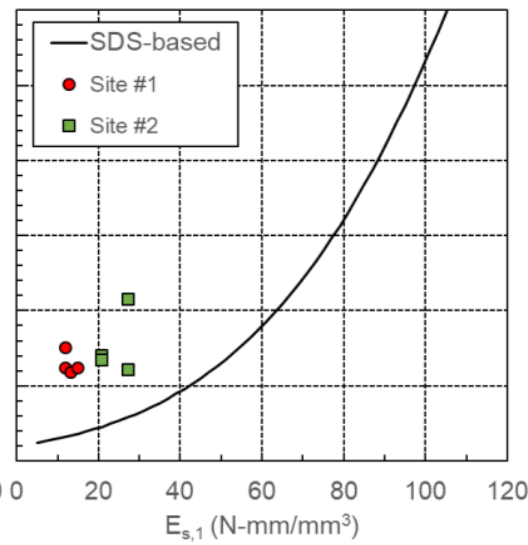

(c)

Figure 12. Comparison between lab-obtained and field-based CRR: (a) using CPT (from [7]; (b) using Vs (from [11]; (c) using SDS from [6].

To further illustrate the effect of using field-derived parameters in estimating the liquefaction resistance of pumice-rich soils, a comparison is made between the $F o S$ estimated using $(C R R)_{\text {field }}$ and that computed using $(C R R)_{l a b}$ at the sampling locations, corresponding to the conditions described in Figures 5 and 6 . For clarity, only the two more popular methods, the CPT-based and $V_{s}$-based approaches are considered. Figure 13 illustrates the comparison. As mentioned earlier, while $0.3 \leq F o S \leq 0.5$ have been estimated for field-based methods, the use of laboratory-obtained $C R R$ would result in increase in $F o S$ by as much as $200 \%$. While liquefaction would still occur at both sites, the estimated severity of liquefaction would decrease, and would better reflect the observed manifestations following the 1987 earthquake.

The observation that even the $V_{s}$-based approach also underestimated the $C R R$ is contrary to the initial finding reported by Orense \& Pender [4], where their observation showed good correlation between laboratory-derived and $V_{s^{-}}$ based $C R R$ (derived using the chart proposed by Andrus and Stokoe, [10]). Their contention then was that although the $V_{s}$ they used was obtained from seismic dilatometer test (sDMT) where the penetrating rod may have induced particle breakage in the pumice zone adjacent to the rod, the shear waves travelled

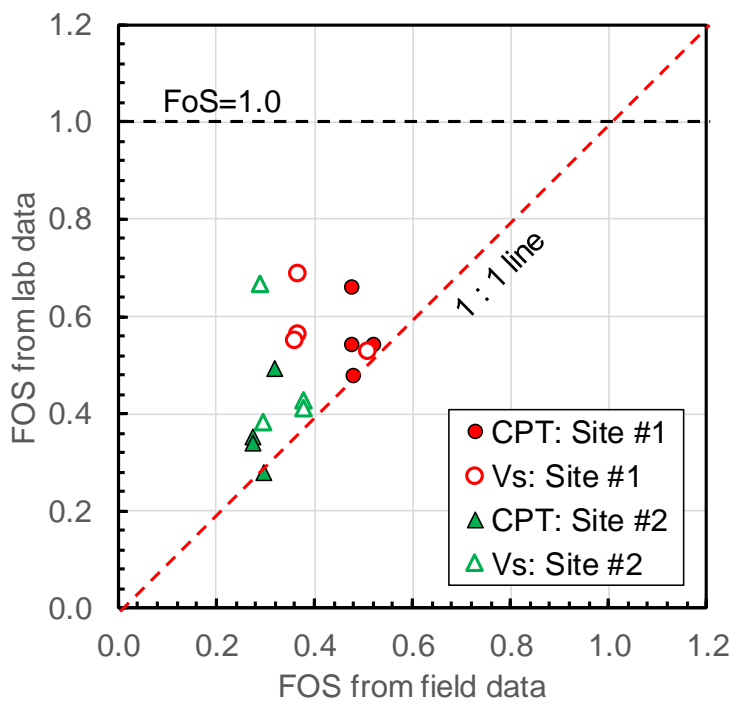

Figure 13: Comparison of FoS using CRR from the field data and from laboratory results, corresponding to the conditions described in Figures 5 and 6. through the intact grains and not on the crushed ones, and therefore the $V_{s}$ measured reflected the actual state of the ground. However, with the data obtained from Site \#1 and Site $\# 2$, the present trend seems to indicate otherwise.

To clarify this, Asadi et al. [20] conducted a parallel research where they noted that under similar relative density, $D_{r}$, and effective confining pressure, $\sigma_{c}^{\prime}$, pumice-rich sands have considerably lower $V_{s}$ when compared to that of hard-grained sands due to the presence of crushable, porous and lightweight pumice particles with irregular surface texture. Moreover, under similar $D_{r}$ and $\sigma_{c}^{\prime}$, the liquefaction resistance of pumicerich sands was higher than that of hard-grained sand due to the complex surface texture and the occurrence of particle crushing during cyclic loading, which resulted in more stable soil structure during cyclic load application. As a result, they concluded that the $C R R_{\text {field }}-V_{s 1}$ relations for pumice-rich sands would plot considerably to the left side of data for hard-grained sands, more or less similar to the trend shown in Figure $12 \mathrm{~b}$. Thus, the current available $C R R-V_{s}$ curves developed for hardgrained sands would result in significant underestimation of the liquefaction resistance of pumice-rich sands.

\section{CONCLUDING REMARKS}

In order to investigate whether existing empirical field-based methods to evaluate liquefaction potential of sands, which were originally developed for hard-grained soils, are applicable to crushable pumice-rich deposits, two sites were selected where liquefaction had been observed following the 1987 Edgecumbe earthquake. Manifestations of soil liquefaction, such as sand boils and ejected materials, have been reported at both sites. Field tests, including cone penetration tests (CPT), shear-wave velocity profiling through seismic $\mathrm{CPT}$, and screw driving sounding (SDS) tests were performed at the sites. Then, considering estimated peak ground accelerations (PGAs) at the site based on recorded motions following the 1987 earthquake and possible range of ground water table locations, liquefaction analyses were conducted at the sites using available empirical chart-based approaches.

Using the simplified empirical-based methods, both sites showed that all methods considered would predict liquefaction of pumice at depth, ranging from the location of the water table up to the maximum depth. While these assessments were consistent with the observed occurrence of liquefaction at the sites, the severity of liquefaction-induced damage, as indicated by the very low factor of safety against liquefaction $(F o S)$, would not explain the minor-to-moderate degree of damage 
reported at the sites. A possible explanation was that the current empirical methods appeared to underestimate the liquefaction resistance of the pumice-rich sands.

To investigate further, high-quality undisturbed soil sampling was conducted at both sites, and the samples obtained were tested in the laboratory using undrained cyclic triaxial apparatus. Comparison of the liquefaction resistances obtained from undisturbed samples with those estimated using field parameters ( $q_{c}$ from CPT, $V_{s}$ and $E_{s}$ from SDS) indicated that the latter provides an underestimation.

The results clearly showed that pumice-rich sands do not fit existing frameworks for liquefaction assessment and alternate methods are necessary to characterise them. Until a more appropriate method is formulated, obtaining high-quality undisturbed soil samples of pumice-rich soils and performing laboratory undrained cyclic tests on these samples are the best ways to estimate their liquefaction resistance. The quality of the recovered samples should be evaluated either qualitatively (e.g., through visual inspection) or quantitatively (e.g., through comparison of field-obtained and laboratory-derived shear wave velocities), preferably both on site immediately after sampling and in the laboratory, in order to assess if potential disturbance (due to sampling, handling and transport) has affected the quality of the samples.

\section{ACKNOWLEDGMENTS}

The support of Whakatane District Council, AECOM and GNS Science in determining the target test sites is gratefully acknowledged. Same with the owner of the farm where Site \#2 was located. The assistance of Dr. Y Mirjafari, Dr MS Asadi and Ms N Papen in conducting the sampling and running some of the cyclic triaxial tests is also acknowledged. This project was supported by the Natural Hazard Research Platform (NHRP) and by the QuakeCoRE, a New Zealand Tertiary Education Commission-funded Centre. This is QuakeCoRE Publication Number 0518.

\section{REFERENCES}

1 Pender MJ and Robertson TW, eds. (1987). "Edgecumbe Earthquake: Reconnaissance Report". Bulletin of the New Zealand National Society for Earthquake Engineering, 20 (3): 201-249.

2 Wesley LD, Meyer VM, Pronjoto S, Pender MJ, Larkin TJ and Duske GC (1999). "Engineering properties of pumice sand". Proc., 8th Australia-NZ Conference on Geomechanics, Hobart, 2: $901-908$.

3 Orense RP, Pender MJ and O'Sullivan A (2012). "Liquefaction Characteristics of Pumice Sands". Final Report of EQC Project 10/589, 131pp.

4 Orense RP and Pender MJ (2013). "Liquefaction characteristics of crushable pumice sand". Proc. 18th International Conference on Soil Mechanics and Geotechnical Engineering, Paris, 4pp.

5 Orense RP, Mirjafari Y and Suemasa N (2019). "Screw Driving Sounding: A new test for field characterisation". Geotechnical Research, 6(1): 28-38.

6 Mirjafari Y, Orense RP and Suemasa N (2016). "Soil classification and liquefaction evaluation using Screw Driving Sounding". Proc., 5th International Conference on Geotechnical and Geophysical site Characterisation, Gold Coast, Australia, 6pp.
7 Boulanger RW and Idriss IM (2014). "CPT and SPT based Liquefaction Triggering Procedures". Report No. UCD/CGM-14/01, Center for Geotechnical Modeling, Department of Civil and Environmental Engineering, University of California, Davis, CA, 134 pp.

8 Robertson PK and Cabal KL (2012). Guide to Cone Penetration Testing for Geotechnical Engineering, 5th Edition, Gregg Drilling \& Testing, 131pp.

9 Moss RES, Seed RB, Kayen RE, Stewart JP, Der Kiureghian A and Cetin KO (2006). "CPT-based probabilistic and deterministic assessment of in situ seismic soil liquefaction potential”. Journal of Geotechnical and Geo-environmental Engineering, 132(8): 1032-1051.

10 Andrus RD and Stokoe KH II (2000). "Liquefaction resistance of soils from shear-wave velocity". Journal of Geotechnical and Geo-environmental Engineering, 126(11): 1015-1025.

11 Kayen RE, Moss RES, Thompson EM, Seed RB, Cetin KO, Der Kiureghian A, Tanaka Y and Tokimatsu K (2013). "Shear-wave velocity-based probabilistic and deterministic assessment of seismic soil liquefaction potential". Journal of Geotechnical and Geo-environmental Engineering, 139(3): 407-419.

12 Mellsop N (2017). "Liquefaction Case Histories from the 1987 Edgecumbe Earthquake -Insights from an Extensive CPT Dataset, Direct Push Cross Hole Shear and Compression Wave Velocity (VsVp) Testing and PaleoLiquefaction Trenching". ME Thesis, University of Auckland.

13 Iwasaki T, Tokida K, Tatsuoka F and Yasuda S (1978). “A practical method for assessing soil liquefaction potential based on case studies at various sites in Japan”. Proc. 2nd International Conference on Microzonation, San Francisco, 885-896.

14 Tonkin \& Taylor (2013). "Liquefaction Vulnerability Study". Report Submitted to the Earthquake Commission, February 2013 Ref 52020.0200 v1.0.

15 Mori K and Sakai K (2016). "The GP sampler: a new innovation in core sampling". Journal of the Australian Geomechanics Society, 51(4): 131-166.

16 Stringer ME, Orense RP, Pender MJ and Haycock I (2018). "Undisturbed sampling of pumiceous deposits in New Zealand". Proc. Geotechnical Earthquake Engineering and Soil Dynamics V (GSP 293), Austin, Texas, 394-403.

17 Stringer ME, Asadi MB, Orense RP, Asadi MS and Pender MJ (2019). "Cyclic behavior of undisturbed samples from pumice-rich soils". Proc., 7th International Conference on Earthquake Geotechnical Engineering, Rome, Italy, 51125119.

18 Ishihara K (1985). "Stability of natural deposits during earthquakes". Proc., 11th International Conference on Soil Mechanics \& Foundation Engineering, San Francisco, CA, 1: 321-376.

19 Towhata I (2008). Geotechnical Earthquake Engineering. Springer Science \& Business Media, Berlin.

20 Asadi MB, Asadi MS, Orense RP and Pender MJ (2018). "Shear wave velocity-based assessment of liquefaction resistance of natural pumiceous sands". Géotechnique Letters, 8(4): 1-6. 